LEITE, R. C.; TOMQUELSKI, G. V.; GUAZINA, R. A.; LEAL, A. J. F. Controle químico de Conyza bonariensis em dessecação. Revista de Agricultura Neotropical, Cassilândia-MS, v. 1, n. 2, p. 64-71, out./dez. 2014.

\title{
CONTROLE QUÍMICO DE Conyza bonariensis EM DESSECAÇÃO
}

\section{RAFAEL DA COSTA LEITE, GERMISON VITAL TONQUELSKI, RENATO ANASTÁCIO GUAZINA, AGUINALDO JOSÉ FREITAS LEAL}

\begin{abstract}
RESUMO: A buva (Conyza bonariensis) é uma das principais plantas infestantes no agroecossistema brasileiro, demandando novas alternativas de manejo a cada safra. O objetivo desse trabalho foi avaliar o desempenho de diferentes programas de aplicação de herbicidas na dessecação de área experimental infestada com buva. $\mathrm{O}$ experimento foi conduzido em condições de campo, no município de Chapadão do Sul, MS. O delineamento experimental foi em blocos casualizados com 26 tratamentos e quatro repetições. A eficiência de controle dos tratamentos foi determinada pelo método de avaliação visual, atribuindo-se notas em porcentagem de controle. Glufosinato-Sal de Amônio + Óleo Mineral (T21) apresentou a maior eficiência no controle da buva. Os tratamentos, 2,4 D + Glifosato (T9), 2,4 D + Glifosato (T10), (Paraquate+Diurom) + Óleo Mineral (T20), Saflufenacil + Glifosato 35+1800 (T24), Saflufenacil + Glifosato (T25) e 2,4 D + Glifosato + Oleo de casca de laranja (T26) são importantes opções de controle, permitindo uma rotação de princípios ativos.
\end{abstract}

PALAVRAS-CHAVE: buva, rotação de herbicidas, plantio direto, herbicidas.

\section{Conyza bonariensis CHEMICAL CONTROL BY DESICCATION}

\begin{abstract}
The horseweed (Conyza bonariensis) is one of the major weed in Brazilian agro-ecosystem, demanding new management alternatives in each crop. The aim of this study was to evaluate the performance from different herbicide desiccation programs in infested area with horseweed. The experiment was conducted under field conditions in the municipality of Chapadao do Sul (Mato Grosso do Sul State). The experimental design was a randomized block with 26 treatments and four replications. The control of treatments efficiency was determined by visual assessment method, assigning grades in percentages of control. Glufosinate-Salt of Ammonium + Mineral Oil (T21) showed the highest efficiency in the horseweed control. The treatments, 2.4 D + Glyphosate (T9), 2.4 D + Glyphosate (T10), (Paraquat + Diuron) + Mineral Oil (T20), Saflufenacil Glyphosate 35 + 1800 (T24), Saflufenacil + Glyphosate (T25 ) and 2.4 D + Glyphosate + Orange peel oil (T26) are important control options, allowing a rotation of active ingredients.
\end{abstract}

KEY-WORDS: horseweed, herbicides rotation, no-tillage, herbicides.

\section{INTRODUÇÃO}

O sistema plantio direto foi iniciado no Brasil na década de 1970 com o objetivo de reduzir as perdas de solo por erosão, por meio da redução do revolvimento do solo e propiciar a formação de cobertura morta, a qual pode ser constituída por restos vegetais das culturas, por forrageiras destinadas ao pastoreio ou por culturas manejadas para essa finalidade ou adubos verdes (ARAÚJO; RODRIGUES, 2000; PRAGANA et al., 2012). Atualmente esse sistema é muito utilizado no Brasil, no ano de 2012 estima-se que a área alcançou a mais de 31 milhões de hectares, segundo a Federação Brasileira de Plantio Direto na Palha (FEBRAPDP, 2014). 
Nesse sistema o uso de herbicidas é indispensável para o manejo de plantas daninhas antes da semeadura. Muitas vezes, no entanto, a utilização da área em cultivos de inverno não possibilita adequada cobertura na superfície do solo, necessária para a semeadura da safra de verão e o manejo destinado à semeadura do próximo cultivo é realizado sobre infestação constituída por plantas daninhas. Esse é o caso, bastante comum, das áreas de plantio direto do Centro-Sul do Brasil, nas quais o milho de segunda safra é cultivado. Uma vez que o ciclo desse cultivo normalmente se inicia em fevereiro e termina entre junho e agosto, existe sempre um período razoável de tempo entre a colheita do milho e a semeadura da cultura de verão seguinte (iniciada em outubro), o que proporciona a emergência e o crescimento das plantas daninhas (SEVERINO et al., 2006).

As estratégias mais comuns utilizadas no manejo tanto das culturas de cobertura quanto da vegetação infestante nas áreas de plantio direto resumem-se a três: a dessecação imediatamente antes da semeadura; entre sete e dez dias antes da semeadura ou a dessecação antecipada (OLIVEIRA et al., 2006). A combinação dos fatores adoção de plantio direto e a possibilidade de uso do herbicida glifosato antes e após a semeadura em cultivares tolerantes ao mesmo, aumentou a pressão de seleção exercida por esse herbicida e, consequentemente, o risco de aparecimento de plantas daninhas resistentes (NEVE et al., 2003).

O primeiro relato de resistência no gênero Conyza foi de biótipos de C. canadensis ao glifosato nos Estados Unidos. Desde então, outros biótipos de buva resistentes foram encontrados em diferentes estados norte-americanos e em diversos países (VANGESSEL, 2001). No Brasil, foram confirmados casos de resistência de biótipos de Conyza bonariensis, C. canadenses e Conyza sumatrensis ao herbicida glifosato (MOREIRA et al., 2007; VARGAS et al., 2007; LAMEGO; VIDAL, 2008; SANTOS et al., 2014).

A adoção de técnicas de manejo no período de entressafra (período entre a colheita do milho safrinha e a semeadura da soja no verão) que conciliem o controle químico com herbicidas de alto espectro de ação associados à herbicidas com atividade residual, combinados com o controle cultural, como a utilização de plantas de cobertura de inverno, é parte fundamental para o manejo de biótipos de $C$. bonariensis resistentes ao glifosato (OLIVEIRA NETO et al., 2010).

Com base no exposto, objetivou-se com este trabalho avaliar o desempenho de diversos herbicidas em dessecação de plantas de Conyza bonariensis.

\section{MATERIAL E MÉTODOS}

O experimento foi conduzido, no município de Chapadão do Sul, MS, em setembro de 2013. O solo da área experimental é classificado como Latossolo Vermelho Distrófico, textura argilosa e o clima é classificado como $\mathrm{A}_{\mathrm{w}}$, segundo a classificação de Köppen, tropical úmido, com estação chuvosa no verão e seca no inverno, precipitação pluviométrica anual média de $1.850 \mathrm{~mm}$ concentrada nos meses de Outubro a Abril.

O delineamento experimental utilizado foi o de blocos ao acaso, com quatro repetições. As parcelas foram constituídas por uma área de $6 \mathrm{~m}$ de largura e 7 metros de comprimento, perfazendo área de $42 \mathrm{~m}^{2}$ por parcela, com 4 repetições totalizando $168 \mathrm{~m}^{2}$ por tratamento. A área encontrava-se somente com a presença da planta daninha alvo do experimento, em restos da cultura do milho, realizado anteriormente. Estes restos culturais cobriam $25 \%$ do solo.

Os tratamentos consistiram na aplicação dos seguintes herbicidas e suas respectivas doses (g) de ingrediente ativo por hectare: T1- testemunha; T2- Atrazina 1500; T3- Atrazina 
2000; T4- Tembotriona 63; T5- Tembotriona 105; T6-Clorimurom-Etílico 20 + Glifosato 1800; T7- Clorimurom-Etílico 30 + Glifosato 1800; T8- 2,4 D 1209; T9- 2,4 D 806 + Glifosato 1440; T10- 2,4 D 1209 + Glifosato 1440; T11- Imazetapir 90 + 1440; T12Imazetapir + Glifosato 60 + 1800; T13- Imazetapir + Glifosato 90 + 1800; T14- Diclosulam 33,6; T15- Diclosulam + Glifosato 25,2 + 1800; T16- Diclosulam + Glifosato 33,6 + 1800; T17- Glifosato 1080; T18- Glifosato 1800; T19- Fluroxypyr + Clopyralid 144+200; T20Paraquate + Diurom + Óleo Mineral $500+250+214$; T21- Glufosinato-Sal de Amônio + Óleo Mineral $600+128,4$; T22- Nicosulfurom 30; T23- Saflufenacil 49; T24- Saflufenacil + Glifosato 35+1800; T25- Saflufenacil + Glifosato 49+1800 e T26 2,4 D + Glifosato + Óleo de Casca de Laranja 1005+1440+1000.

As aplicações dos tratamentos foram realizadas utilizando pulverizador costal pressurizado $\mathrm{CO}_{2}$, com pontas AXI 11002, distanciadas a $0,5 \mathrm{~m}$ entre si, mantido à pressão de trabalho de 3,0 $\mathrm{kgf} \mathrm{cm}^{-2}$, que resultou em consumo de calda equivalente a $150 \mathrm{~L} \mathrm{ha}^{-1}$. As condições por ocasião da aplicação apresentavam umidade relativa média de $53 \%$ e temperatura média de $28,4{ }^{\circ} \mathrm{C}$. Na área a última precipitação ocorreu em 13 dias anterior à aplicação.

As avaliações de eficácia agronômica foram efetuadas aos 7, 14 e 21 dias após a aplicação (DAA), empregando-se a escala percentual, em que $0 \%$ representa nenhum controle e $100 \%$, ao controle total das plantas daninhas comparados à testemunha sem aplicação (ALAM, 1974). Foram atribuídas notas de controle separadas em plantas daninhas pequenas (altura inferior a $15 \mathrm{~cm}$ ) e plantas grandes (mais de $15 \mathrm{~cm}$ de altura). A espécie de $C$. bonariensis foi identificada utilizando-se as informações de Lorenzi (2006) e Constantin et al. (2013). Os dados obtidos foram submetidos à análise de variância, sendo as médias comparadas pelo teste de Scott-Knott a 5\% de probabilidade.

\section{RESULTADOS E DISCUSSÃO}

$\mathrm{Na}$ avaliação de eficiência de controle aos 7 DAA (dias após a aplicação), para ambas as alturas de plantas (menores ou maiores que $15 \mathrm{~cm}$ ), os tratamentos 20 $\left((\right.$ Paraquate+Diurom $)+$ Óleo Mineral, dose 2,5 + 0,5 L.ha $^{-1}$ respectivamente $)$ e 21 (Glufosinato-Sal de Amônio + Óleo Mineral, dose 3,0 + 0,3 $\mathrm{L} \mathrm{ha}^{-1}$ ) apresentaram as melhores médias de controle diferindo significativamente dos demais tratamentos (Tabela 1).

Na segunda avaliação, aos 14 DAA, tanto para plantas de buva maiores e menores do que $15 \mathrm{~cm}$, a maior eficiência foi obtida com a utilização de Glufosinato-Sal de Amônio + Óleo Mineral (T21), seguido do tratamento Paraquate+Diurom + Óleo Mineral (T20). Ainda na avaliação aos 14 DAA os tratamentos 2,4 D 806 + Glifosato 1440 (T9), 2,4 D + Glifosato (T10), Saflufenacil + Glifosato 35+1800 (T24), Saflufenacil + Glifosato (49 + 1800) (T25) e 2,4 D + Glifosato + Óleo de casca de laranja (T26) apresentaram controle igual ou superior a $65 \%$ não diferindo entre si (Tabela 1 ).

$\mathrm{Na}$ avaliação realizada aos 21 DAA, a maior eficiência de controle foi obtida com Glufosinato-Sal de Amônio + Óleo Mineral (T21), diferindo significativamente dos demais tratamentos (Tabela 1), para plantas maiores e menores do que $15 \mathrm{~cm}$. Um segundo grupo de tratamentos promissores como alternativas de rotação de produtos foi composto por tratamentos 2,4 D 806 + Glifosato 1440 (T9), 2,4 D + Glifosato (T10), Paraquate+Diurom + Óleo Mineral (T20), Saflufenacil + Glifosato 35+1800 (T24), Saflufenacil + Glifosato (49 + 1800) (T25) e 2,4 D + Glifosato + Óleo de casca de laranja (T26) com controle superior ou igual a $65 \%$ (Tabela 1$)$. 
Tabela 1. Porcentagem de eficiência obtida nos tratamentos, adotados sobre a buva (Conyza bonariensis). Chapadão do Sul, MS, Setembro de 2013.

\begin{tabular}{|c|c|c|c|c|c|c|c|c|}
\hline \multirow{2}{*}{ Tratamento } & \multirow{2}{*}{ Ingrediente Ativo } & \multirow{2}{*}{$\underset{1}{\left.{ }_{1}\right)}$} & \multicolumn{3}{|c|}{$>15 \mathrm{~cm}$} & \multicolumn{3}{|c|}{$<15 \mathrm{~cm}$} \\
\hline & & & 7 daa & 14 daa & 21 daa & 7 daa & 14 daa & 21 daa \\
\hline T1 - Testemunha & - & - & $0 \mathrm{i}$ & $0 \mathrm{~h}$ & $0 \mathrm{j}$ & $0 \mathrm{i}$ & $0 \mathrm{i}$ & $0 \mathrm{j}$ \\
\hline $\mathrm{T} 2$ - Atrazina 500 Nortox & Atrazina & 1500 & $10 \mathrm{~h}$ & $15 \mathrm{~g}$ & $15 \mathrm{~h}$ & $10 \mathrm{~h}$ & $10 \mathrm{~h}$ & $10 \mathrm{i}$ \\
\hline T3 - Atrazina 500 Nortox & Atrazina & 2000 & $10 \mathrm{~h}$ & $18 \mathrm{~g}$ & $13 \mathrm{i}$ & $10 \mathrm{~h}$ & $15 \mathrm{~g}$ & $10 \mathrm{i}$ \\
\hline T4 - Soberan & Tembotriona & 63 & $10 \mathrm{~h}$ & $23 \mathrm{f}$ & $13 \mathrm{i}$ & $10 \mathrm{~h}$ & $20 \mathrm{~g}$ & $13 \mathrm{i}$ \\
\hline T5 - Soberan & Tembotriona & 105 & $13 \mathrm{~h}$ & $23 \mathrm{f}$ & $18 \mathrm{~h}$ & $13 \mathrm{~h}$ & $20 \mathrm{~g}$ & $18 \mathrm{~h}$ \\
\hline T6 - Clorimuron Nortox + Roundup WG & $\begin{array}{c}\text { Clorimurom-Etílico }+ \\
\text { Glifosato }\end{array}$ & $20+1800$ & 30 e & 38 e & $38 \mathrm{e}$ & $30 \mathrm{e}$ & 33 e & $38 \mathrm{f}$ \\
\hline T7 - Clorimuron Nortox + Roundup WG & $\begin{array}{c}\text { Clorimurom-Etílico + } \\
\text { Glifosato }\end{array}$ & $30+1800$ & $28 \mathrm{e}$ & 35 e & $38 \mathrm{e}$ & $28 \mathrm{e}$ & $35 \mathrm{e}$ & $35 \mathrm{f}$ \\
\hline $\mathrm{T} 8-2,4 \mathrm{D}$ & $2,4 \mathrm{D}$ & 1209 & $38 \mathrm{~d}$ & $40 \mathrm{e}$ & $45 \mathrm{~d}$ & $38 \mathrm{~d}$ & $38 \mathrm{e}$ & $43 \mathrm{e}$ \\
\hline T9 - 2,4 D + Roundup WG & 2,4 D + Glifosato & $806+1440$ & $50 \mathrm{c}$ & $73 \mathrm{c}$ & $70 \mathrm{~b}$ & $50 \mathrm{c}$ & $70 \mathrm{c}$ & $70 \mathrm{~b}$ \\
\hline T10 - 2,4 D + Roundup WG & 2,4 D + Glifosato & $1209+1440$ & $55 \mathrm{~b}$ & $73 \mathrm{c}$ & $70 \mathrm{~b}$ & $55 \mathrm{~b}$ & $73 \mathrm{c}$ & $70 \mathrm{~b}$ \\
\hline T11 - Pivot & Imazetapir & $90+1440$ & $23 \mathrm{f}$ & $23 \mathrm{f}$ & $15 \mathrm{~h}$ & $23 \mathrm{f}$ & $25 \mathrm{f}$ & $15 \mathrm{~h}$ \\
\hline T12 - Pivot + Roundup WG & Imazetapir + Glifosato & $60+1800$ & $25 \mathrm{f}$ & $38 \mathrm{e}$ & 38 e & $25 \mathrm{f}$ & $38 \mathrm{e}$ & $38 \mathrm{f}$ \\
\hline T13 - Pivot + Roundup WG & Imazetapir + Glifosato & $90+1800$ & $28 \mathrm{e}$ & $48 \mathrm{~d}$ & $58 \mathrm{c}$ & $28 \mathrm{e}$ & $48 \mathrm{~d}$ & $58 \mathrm{~d}$ \\
\hline
\end{tabular}




\begin{tabular}{|c|c|c|c|c|c|c|c|c|c|c|}
\hline T14 - Spider & Diclosulam & 33,6 & $20 \mathrm{G}$ & $23 \mathrm{f}$ & $23 \mathrm{~g}$ & 20 & $\mathrm{~g}$ & 23 & $\mathrm{f}$ & $23 \mathrm{~h}$ \\
\hline T15 - Spider + Roundup WG & Diclosulam + Glifosato & $25,2+1800$ & $13 \mathrm{~h}$ & $18 \mathrm{~g}$ & $13 \mathrm{i}$ & 13 & h & 15 & $\mathrm{~g}$ & $13 \mathrm{i}$ \\
\hline T16 - Spider + Roundup WG & Diclosulam + Glifosato & $33,6+1800$ & $10 \mathrm{~h}$ & $15 \mathrm{~g}$ & $10 \mathrm{i}$ & 10 & h & 10 & $\mathrm{~h}$ & $10 \mathrm{i}$ \\
\hline T17 - Roundup WG & Glifosato & 1080 & $13 \mathrm{~h}$ & $20 \mathrm{~g}$ & $10 \mathrm{i}$ & 13 & $\mathrm{~h}$ & 18 & $\mathrm{~g}$ & $10 \mathrm{i}$ \\
\hline T18 - Roundup WG & Glifosato & 1800 & $20 \mathrm{~g}$ & $25 \mathrm{f}$ & $18 \mathrm{~h}$ & 20 & $\mathrm{~g}$ & 23 & $\mathrm{f}$ & $18 \mathrm{~h}$ \\
\hline T19 - Prestige & Fluroxypyr+Clorpyralid & $144+200$ & $20 \mathrm{~g}$ & $28 \mathrm{f}$ & $28 \mathrm{f}$ & 20 & $\mathrm{~g}$ & 25 & $\mathrm{f}$ & $28 \mathrm{~g}$ \\
\hline T20 - Gramocil + Nimbus & $\begin{array}{l}\text { (Paraquate+Diurom })+ \\
\text { Óleo Mineral }\end{array}$ & $500+250+214$ & $70 \mathrm{a}$ & $80 \mathrm{~b}$ & $73 \mathrm{~b}$ & 70 & $\mathrm{a}$ & 80 & $\mathrm{~b}$ & $73 \mathrm{~b}$ \\
\hline T21 - Finale + Nimbus & $\begin{array}{c}\text { Glufosinato-Sal de } \\
\text { Amônio + Óleo Mineral }\end{array}$ & $600+128,4$ & $70 \mathrm{a}$ & $90 \mathrm{a}$ & $90 \mathrm{a}$ & 70 & $\mathrm{a}$ & 90 & $\mathrm{a}$ & $90 \mathrm{a}$ \\
\hline T22 - Nicosulfuron Nortox & Nicosulfurom & 30 & $20 \mathrm{~g}$ & $28 \mathrm{f}$ & $25 \mathrm{~g}$ & 20 & $\mathrm{~g}$ & 25 & $\mathrm{f}$ & $25 \mathrm{~g}$ \\
\hline T23 - Heat & Saflufenacil & 49 & $15 \mathrm{~h}$ & $43 \mathrm{~d}$ & $43 \mathrm{~d}$ & 15 & $\mathrm{~h}$ & 35 & $\mathrm{e}$ & 43 e \\
\hline T24 - Heat + Roundup WG & Saflufenacil + Glifosato & $35+1800$ & $25 \mathrm{f}$ & $65 \mathrm{c}$ & $65 \mathrm{~b}$ & 25 & $\mathrm{f}$ & 65 & $\mathrm{c}$ & $65 \mathrm{c}$ \\
\hline T25 - Heat + Roundup WG & Saflufenacil + Glifosato & $49+1800$ & $30 \mathrm{e}$ & $70 \mathrm{c}$ & $68 \mathrm{~b}$ & 30 & $\mathrm{e}$ & 70 & c & $65 \mathrm{c}$ \\
\hline $\begin{array}{l}\text { T26 - 2,4 D + Roundup WG + Óleo de } \\
\text { casca de laranja }\end{array}$ & $\begin{array}{l}\text { 2,4 D + Glifosato + Óleo } \\
\text { de casca de laranja }\end{array}$ & $1005+1440+1000$ & $50 \mathrm{c}$ & $73 \mathrm{c}$ & $70 \mathrm{~b}$ & 50 & $\mathrm{c}$ & 73 & $\mathrm{c}$ & $70 \mathrm{~b}$ \\
\hline $\mathrm{CV}(\%)$ & - & - & $12 \%$ & $\begin{array}{r}12, \% \\
9\end{array}$ & $\begin{array}{r}11, \% \\
3\end{array}$ & $\begin{array}{r}11 \\
9 \\
\end{array}$ & $\%$ & $\begin{array}{r}11, \\
1\end{array}$ & $\%$ & $\begin{array}{r}11, \\
7\end{array}$ \\
\hline
\end{tabular}

Valores acompanhados de mesma letra na coluna e para a mesma variável não diferem entre si significativamente pelo teste de Scott-Knott (5\%); 
Resultados semelhantes foram observados por Moreira et al. (2010). Esses autores verificaram que o controle $C$. bonariensis e $C$. canadensis foram eficientes quando da utilização do herbicida Glufosinato-Sal de Amônio. Eubank et al. (2008) ao trabalhar com uma população de $C$. canadensis resistente ao glifosato no Mississippi, EUA, também obteve resultados semelhantes de controle.

Os tratamentos 2, 3, 4 e 5 com os herbicidas Atrazina e Tembotrione, apresentaram baixa eficiência no controle da buva (Tabela 1). Esses herbicidas são muitos utilizados no controle de outras plantas daninhas na cultura do milho em cultivo de segunda safra, porém como observado, esses herbicidas pouco contribuem para o controle de buva.

Algumas populações de $C$. canadensis na Hungria, EUA e em Israel já desenvolveram resistência ao herbicida atrazine, devido ser amplamente utilizado na cultura do milho, segundo Lehoczki et al. (1984) e Lazaroto et al. (2008). Portanto, a rotação de herbicidas é fundamental no manejo dessa planta daninha. Nesse sentido, apesar dos melhores resultados do tratamento com Glufosinato-Sal de Amônio os demais tratamentos herbicidas (Paraquate+Diurom) + Óleo Mineral (T20), 2,4 D + Glifosato (T9 e T10) e Saflufenacil + Glifosato (T24 e 25), que também apresentam controle, não podem ser descartados em um sistema de rotação.

No presente trabalho fica evidente que a associação de herbicidas no controle de $C$. bonariensis tem apresentado bons resultados de controle. Uma associação promissora são as associações de glifosate com 2,4-D, concordando com Lamego e Vidal (2008) que apontaram grande eficiência com a associação glifosate com 2,4-D e chlorimuron-ethyl no controle de buva.

Outro fator que deve ser avaliado são as possíveis contribuição de outras práticas de manejo para controle dessa planta daninha. Como uma maior produção de palha no sistema plantio direto, utilizando culturas de cobertura e rotação de culturas, pouco realizados no Brasil. Essa última em estudo realizado por Barnes et al. (2004), como uma das alternativas para o manejo de $C$. canadenses em Indiana, EUA apresentou baixa eficiência, mas segundo os autores contribui no manejo da mesma. Provavelmente, isso se deve a grande adaptabilidade dessa planta daninha a diferentes cultivos.

A prática da rotação é dificultada em função de outras culturas que podem ser cultivadas, como o milho e algodão, os quais possuem cultivares resistentes ao glifosato, sendo um herbicida bastante adotado tanto em manejo pré-plantio quanto em pós-emergência da cultura. Nesse sentido, é importância o desenvolvimento de trabalhos que avaliem a associação de herbicidas como apresentado no presente trabalho.

Esse problema também foi destacado por Johnson et al. (2009) ao avaliar a influência do uso de cultivares resistentes ao glifosato sobre a população de plantas daninhas nas culturas de soja, milho, algodão e canola nos Estados. Esses autores relatam que a dinâmica das populações de plantas infestantes foi muito alterada com as frequentes utilizações de glifosato no sistema, diminuindo as gramíneas e espécies de folhas largas e perenes, anteriormente de difícil controle.

\section{CONCLUSÃO}

Glufosinato-Sal de Amônio + Óleo Mineral (T21) apresentou a maior eficiência no controle da buva.

Os tratamentos, 2,4 D + Glifosato (T9), 2,4 D + Glifosato (T10), (Paraquate+Diurom) + Óleo Mineral (T20), Saflufenacil + Glifosato 35+1800 (T24), Saflufenacil + Glifosato 
(T25) e 2,4 D + Glifosato + Oleo de casca de laranja (T26) e são importantes opções de controle, permitindo uma rotação de princípios ativos.

\section{REFERÊNCIAS}

ALAM. ASOCIACION LATINOAMERICANA DE MALEZAS. Recomendaciones sobre unificación de lós sistemas de evaluación en ensayos de control de malezas. ALAM, v.1, n.1, p.35-38, 1974.

ARAÚJO, A. G.; RODRIGUES, B. N. Manejo mecânico e químico da aveia preta e sua influência sobre a taxa de decomposição e o controle de plantas daninhas em semeadura direta de milho. Planta Daninha, Viçosa-MG, v. 18, n. 1, p. 151-160, 2000.

BARNES, J.; JOHNSON, B.; GIBSON, K.; WELLER, S. Crop rotation and tillage system influence late-season incidence of giant ragweed and horseweed in Indiana soybean. Crop Management, Davis, v.3, n.1, 2004.

CONSTANTIN, J.; OLIVEIRA JÚNIOR., R. S.; OLIVEIRA NETO,A. M. Buva: fundamentos e recomendações para manejo. Curitiba: OMNIPAX. 2013. 122p.

EUBANK, T. W.; POSTON, D. H.; NANDUlA, V. K.; KOGER, C. H.; SHAW, D. R.; REYNOLDS, D. B. Glifosato-resistant Horseweed (Conyza canadensis) Control Using Glifosato-, Paraquat-, and Glufosinate-Based Herbicide Programs. Weed Technology, v. 22, n. 1, p. 16-21, 2008.

FBPDP. Federação Brasileira De Plandio Direto Na Palha. Disponível em: http://www.febrapdp.org.br/?i1=34eAcoBnLhRWY05WYsBXY1JXYa12\&i2=4b8QY1JXYfd e\&i3=e46ARQBSZkBSYlJXwece\&i4=\&i5=34eAcoBnLhRWY05WYsBXY1JXYa12\&m=1. Acesso em 10 de janeiro de 2014.

JOHNSON, W. G.; DAVIS, V. M.; KRUGER, G. R.; WELLER, S. C. Influence of glifosatoresistant cropping systems on weed species shifts and glifosato-resistant weed populations. European Journal of Agronomy, Malden, v. 31, n. 3, p. 162-172, 2009.

LAMEGO, F. P.; VIDAL, R. A. Resistência ao glifosato em biótipos de Conyza bonariensis e Conyza canadensis no estado do Rio Grande do Sul, Brasil. Planta Daninha, Viçosa-MG, v. 26, n. 2, p. 467-471, 2008.

LAZAROTO, C. A.; FLECK, N. G.; VIDAL, R. A. Biologia e ecofisiologia de buva (Conyza bonariensis e Conyza canadensis). Ciência Rural, Santa Maria-RS, v. 38, n. 3, p. 852-860, 2008.

LEHOCZKI, E.; LASKAY, G.; SOLYMOSI, P. Resistance to triazine herbicides in horseweed (Conyza canadensis). Weed Science, Lexington, v. 32, n. 6, p. 669-674, 1984.

LORENZI, H. Manual de identificação e controle de plantas daninhas: plantio direto e convencional. 6. ed. Nova Odessa: Plantarum, 2006. 240p.

MOREIRA, M. S.; NICOLI, M.; CARVALHO, S. J. P.; CHRISTOFFOLETI, P. J. Resistência de Conyza canadensis e Conyza bonariensis ao herbicida glifosato. Planta Daninha, Viçosa-MG, v. 25, n. 1, p. 157-164, 2007.

MOREIRA, M. S.; MElO, M. S. C., CARVALHO, S. J. P., NICOLAI, M.; CRHISTOFFOLETI, P. J. Herbicidas alternativos para controle de biótipos de Conyza bonariensis e C. canadensis resistentes ao glyphosate. Planta daninha, Viçosa-MG, v. 28, n.1, p.167-175. 2010 
NEVE, P.; DIGGLE, A. J.; SMITH, F. P.; POWLES, S. B. Simulating evolution of glifosato resistance in Lolium rigidum I: population genetics of a rare resistance trait. Weed Research, v. 43, p. 404-417, 2003.

OLIVEIRA, R. S.; CONSTANTIN, J.; COSTA, J. M.; CAVALIERI, S. D.; ARANTES, J. G. Z.; ALONSO, D. G.; ROSO, A. C.; BIFFE, D. F. Interação entre sistemas de manejo e de controle de plantas daninhas em pós-emergência afetando o desenvolvimento e a produtividade da soja. Planta Daninha, Viçosa-MG, v. 24, n. 4, p. 721-732, 2006.

OLIVEIRA NETO, A. M.; CONSTANTIN, J.; OLIVEIRA, R. S.; GUERRA, N.; DAN, H. A.; ALONSO, D. G.; BLAINSKI, E.; SANTOS, G. Estratégia de manejo de inverno e verão visando ao controle de Conyza bonariensis e Bidens pilosa. Planta Daninha, Viçosa-MG, v. 28, p. 1107-1116, 2010.

PRAGANA, R. B.; RIBEIRO, M. R.; NÓBREGAS, J. C. A.; RIBEIRO FILHO, M. R.; COSTA, J. A. Qualidade física de Latossolos Amarelos sob plantio direto na região do Cerrado piauiense. Revista Brasileira de Ciência do Solo, v. 36, n. 5, p. 1591-1600, 2012.

SANTOS, G.; OLIVEIRA JÚNIOR, R. S.; CONSTANTIN, J.; FRANCISCHINI, A. C.; OSIPE, J. B. Multiple resistance of Conyza sumatrensis to chlorimuronethyl and to glifosato. Planta Daninha, Viçosa-MG, v. 32, n. 2, p. 409-416, 2014.

SEVERINO, F. J.; CARVALHO, S. J. P.; CHRISTOFFOLETI, P. J. Interferências mútuas entre a cultura do milho, espécies forrageiras e plantas daninhas em um sistema de consórcio. II - implicações sobre as espécies forrageiras. Planta Daninha, Viçosa-MG, v. 24, n. 1, p. 45-52, 2006.

VANGESSEL, M. J. Glifosato resistant horseweed from Delaware. Weed Science, v. 49, p. 703-705, 2001.

VARGAS, L.; BIANCHI, M. A.; RIZZARDI, M. A.; AGOSTINETTO, D.; DAL MAGRO, T. Buva (Conyza bonariensis) resistente ao glifosato na região Sul do Brasil. Planta Daninha, Viçosa-MG, v. 25, n. 3, p. 573-578, 2007. 